\title{
GPCR heterodimerization in the reproductive system: functional regulation and implication for biodiversity
}

\section{Honoo Satake*, Shin Matsubara, Masato Aoyama, Tsuyoshi Kawada and Tsubasa Sakai}

Suntory Foundation for Life Sciences, Bioorganic Research Institute, Osaka, Japan

\section{Edited by:}

Hiroyuki Kaiya, National Cerebral and

Cardiovascular Center, Japan

\section{Reviewed by:}

T. John Wu, Uniformed Services University of the Health Sciences, USA

Yumiko Saito, Hiroshima University, Japan

\section{${ }^{*}$ Correspondence:}

Honoo Satake, Suntory Foundation

for Life Sciences, Bioorganic

Research Institute, 1-1-1

Wakayamadai, Shimamoto, Mishima

Osaka 618-8503, Japan

e-mail:satake@sunbor.or.jp
A G protein-coupled receptor (GPCR) functions not only as a monomer or homodimer but also as a heterodimer with another GPCR. GPCR heterodimerization results in the modulation of the molecular functions of the GPCR protomer, including ligand binding affinity, signal transduction, and internalization. There has been a growing body of reports on heterodimerization of multiple GPCRs expressed in the reproductive system and the resultant functional modulation, suggesting that GPCR heterodimerization is closely associated with reproduction including the secretion of hormones and the growth and maturation of follicles and oocytes. Moreover, studies on heterodimerization among paralogs of gonadotropin-releasing hormone $(\mathrm{GnRH})$ receptors of a protochordate, Ciona intestinalis, verified the species-specific regulation of the functions of GPCRs via multiple GnRH receptor pairs. These findings indicate that GPCR heterodimerization is also involved in creating biodiversity. In this review, we provide basic and current knowledge regarding GPCR heterodimers and their functional modulation, and explore the biological significance of GPCR heterodimerization.

Keywords: GPCR, heterodimer, reproduction, diversity hormones

\section{INTRODUCTION}

The development of "omics" technologies and ensuring construction of a variety of databases provide vast information regarding primary sequences and functional domains of genes and proteins in diverse organisms, leading to annotation or prediction of biochemical and pharmacological propensities of novel genes and proteins. Even in this post-genomic era, several functions of proteins have yet to be fully elucidated or predicted. One of the most unpredictable and confounding post-translational protein functions is the heterodimerization of $G$ protein-coupled receptors (GPCRs).

Currently, a wide range of GPCRs have been proved to function not only as monomers or homodimers but also as heterodimers formed after translation. It has been shown that GPCR heterodimerization alters or fine-tunes ligand binding, signaling, and internalization of GPCR protomers (1-9). The greatest difficulty in studies on GPCR heterodimers lies in the lack of procedures for the prediction of either GPCR protomer pairs for heterodimerization or the resultant functional alteration of GPCRs. Consequently, high-throughput analysis of GPCR heterodimers (e.g., "GPCR heterodimerome") has not yet been accomplished. Despite this shortcoming, there have been increasing findings regarding the biological and pathological significance of GPCR heterodimerization.

Reproduction is regulated by diverse neuropeptides and hormones, with the receptors belonging to the GPCR family, e.g., melatonin, kisspeptin, neurokinin B (NKB), gonadotropininhibitory hormone $(\mathrm{GnIH})$, gonadotropin-releasing hormone (GnRH), luteinizing hormone ( $\mathrm{LH}$ ), follicle-stimulating hormone (FSH), and prostanoids (10-13). In vertebrates, these hormones and neuropeptides play crucial roles in the hypothalamuspituitary-gonad (HPG) axis (Figure 1). Furthermore, various species-specific GPCRs for highly conserved cognate hormones or neuropeptides have been identified (14-18, Kawada et al., forthcoming). Collectively, these findings suggest that GPCR heterodimerization participates in the fine-tuning and diversification of reproductive functions. In this article, we provide an overview of GPCR heterodimerization and discuss the implication of GPCR heterodimers in reproductive functions and their diversification.

\section{GPCR PROTOMERS AS ALLOSTERIC MODULATORS}

It is widely accepted that GPCRs can assume various active conformations which enable coupling with distinct $G$ proteins and other associated proteins followed by particular signal transduction cascades $(3,8,19,20)$. Moreover, allosteric effectors interact with GPCRs at binding sites different from those for agonists or antagonists and modulate the conformations of GPCRs, leading to alterations in agonist/antagonist binding affinity or signal transduction $(3,8,19,20)$. Also of significance is that each of the active conformations responsible for individual signaling pathways is not interconvertible (3, 8, 19-21). Combined with experimental evidence that ligand binding and signaling of GPCR protomers are altered via heterodimerization, GPCR heterodimerization is believed to induce protomer-specific modulation (i.e., stabilization or instabilization) of active conformations as an endogenous allosteric modulator. This view is compatible with the fact that a single GPCR protomer acquires diverse biochemical and/or pharmacological properties via heterodimerization with different GPCR partners. 


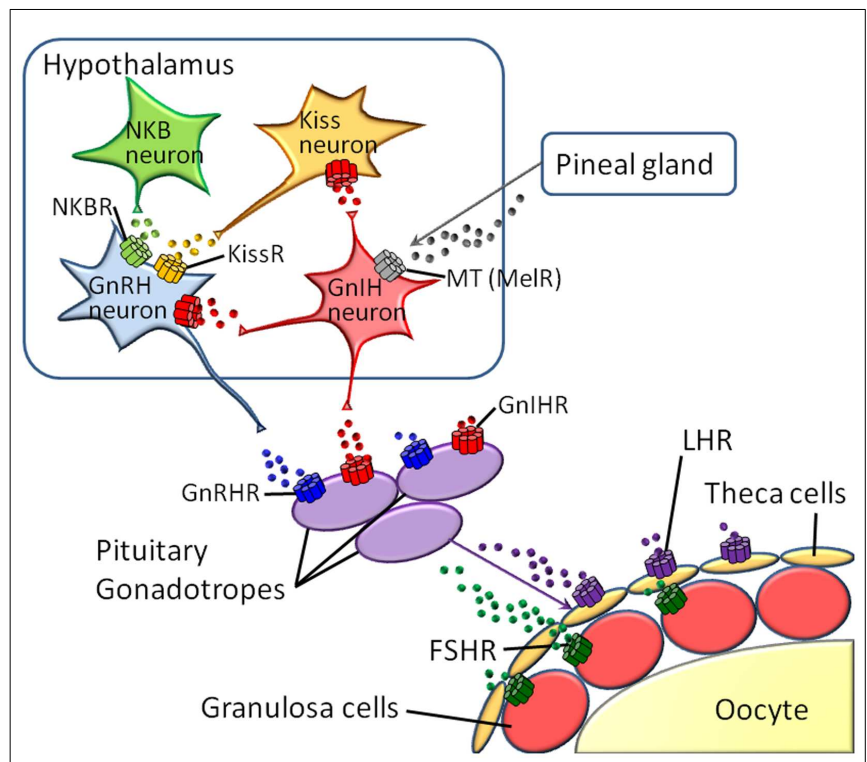

FIGURE 1 | Major GPCRs for neuropeptides or hormones in the hypothalamus-pituitary-gonad (HPG) axis.

\section{TYPICAL FUNCTIONAL CONSEQUENCES OF GPCR HETERODIMERIZATION}

Obviously, colocalization of GPCR protomers in a cell is a prerequisite for the formation of the corresponding GPCR heterodimer in native tissues. However, many early studies demonstrated functional alteration of GPCRs only after co-transfection of cultured cells with two GPCRs but not at the level of endogenous coexpression in the same cells in a particular native tissue. Consequently, the biological and physiological significance of such "in vitro-only" GPCR heterodimers is highly questionable. Consistent with this, the International Union of Basic and Clinical Pharmacology (IUPHAR) release the paradigm for GPCR heterodimer studies in 2007 (2). First, interaction between GPCR protomers in native tissues should be proved by at least two different experimental procedures including co-immunoprecipitation, fluorescence resonance energy transfer (FRET), or bioluminescence resonance energy transfer (BRET). Second, alteration of biochemical or pharmacological functions of GPCRs should be observed in native tissues or co-transfected cells. Third, biological roles of GPCR heterodimers should be verified using geneknockout or gene-silenced procedures. At present, meeting all of these criteria is too difficult. Thus, IUPHAR proposed that researchers fulfill at least two of the three criteria. In the following, we focus on GPCR heterodimers which were detected in native tissues (Table 1).

G protein-coupled receptor heterodimers are classified into two groups in light of their functions: obligatory and nonobligatory GPCR heterodimers. Obligatory GPCR heterodimers require heterodimerization of GPCR protomers to serve as functional receptors, such as gamma amino butyric acid (GABA) type $B$ receptor and taste receptors. $G_{A B A R} B_{1}$ alone is sequestered in the endoplasmic reticulum (ER) due to the presence of an ER retention signal, which is masked by heterodimerization with
Table 1 | Typical functional alteration of GPCRs via heterodimerization.

\begin{tabular}{|c|c|}
\hline Heterodimer & Effect \\
\hline $\mathrm{GABAR}_{\mathrm{B} 1}-\mathrm{GABAR}_{\mathrm{B} 2}$ & $\begin{array}{l}\text { Transition from ER to plasma membrane and } \\
\text { function }\end{array}$ \\
\hline T1R1-T1R3 & Recognition of umami substances \\
\hline T1R2-T1R3 & Recognition of sweet substances \\
\hline AT1-B2 & $\begin{array}{l}\text { Increase of } \mathrm{IP}_{3} \text { accumulation induced by } \\
\text { angiotensin II or bradykinin }\end{array}$ \\
\hline MOR-DOR & $\begin{array}{l}\text { Reduction in binding affinity of Met-enkephalin } \\
\text { Increase in binding affinity of endomorphin-1 and } \\
\text { Leu-enkephalin } \\
\text { Shift of coupling of Gz to Gi }\end{array}$ \\
\hline KOR-DOR & $\begin{array}{l}\text { Enhancement of signaling induced by synthetic } \\
\text { KOR agonists }\end{array}$ \\
\hline OR1-CB1 & $\begin{array}{l}\text { Suppression of OR-triggered ERK phosphorylation } \\
\text { by a CB1 antagonist } \\
\text { Suppression of CB-triggered ERK phosphorylation } \\
\text { by a OR1 antagonist }\end{array}$ \\
\hline MC3R-GHSR & $\begin{array}{l}\text { Increase in cAMP production induced by } \\
\text { melanocortin } \\
\text { Decrease in ghrelin-induced signaling }\end{array}$ \\
\hline D1-D2 & Shift of coupling of $\mathrm{Gs}$ to $\mathrm{Gq} / 11$ \\
\hline MT1-GPR50 & $\begin{array}{l}\text { Decrease of melatonin-binding, } \\
\text { Gi-coupling/signaling, and internalization }\end{array}$ \\
\hline NK1-MOR & $\begin{array}{l}\text { Alternation of internalization and resensitization } \\
\text { profile }\end{array}$ \\
\hline $\mathrm{R} 1-\mathrm{R} 4$ & $\begin{array}{l}\text { Upregulation of ERK phosphorylation via } \\
\mathrm{Ca}^{2+} \text {-dependent PKC } \alpha \text { activation and } \\
\mathrm{Ca}^{2+} \text {-independent } \mathrm{PKC} \zeta \text { activation }\end{array}$ \\
\hline $\mathrm{R} 2-\mathrm{R} 4$ & $\begin{array}{l}\text { Reduction in cAMP production via shift of coupling } \\
\text { of Gs to } \mathrm{Gi}\end{array}$ \\
\hline EP1- $\beta 2 A R$ & $\begin{array}{l}\text { Dissociation of Gs from bA2R induced by EP1 } \\
\text { agonists }\end{array}$ \\
\hline
\end{tabular}

GABAR, GABA receptor; T1R, taste receptor; AT1, angiotensin receptor 1; B2 bradykinin receptor 2; MOR, $\mu$-opioid receptor; DOR, $\delta$-opioid receptor; KOR, к-opioid receptor; OR1, orexin receptor 1; CB1, cannabinoid receptor 1; MC3R, melanocortin receptor 3; GHSR, ghrelin receptor; D1, dopamine receptor 1; MT1, melatonin receptor 1, NK1, tachykinin receptor 1; Ci-GnRHR, Ciona intestinalis GnRH receptor; EP1, prostaglandin E2 receptor 1 .

$\operatorname{GABAR}_{\mathrm{B} 2}$ (22-24). Moreover, the GABAR $\mathrm{B}_{1}$ protomer harbors a ligand-binding site, whereas the $\mathrm{GABAR}_{\mathrm{B} 2}$ protomer merely couples to $G$ proteins $(22-24)$. Therefore, the $\mathrm{GABAR}_{\mathrm{B} 1}-\mathrm{GABAR}_{\mathrm{B} 2}$ heterodimer serves as an authentic GABA receptor. Taste receptors also exhibit heterodimerization-dependent pharmacological profiles. The heterodimer between T1R1 and T1R3 is exclusively responsive to umami taste, while the T1R2-T1R3 heterodimer is a specific receptor for sweet taste-inducing molecules (25-27). 
In contrast, non-obligatory GPCR heterodimers are composed of the functional GPCR protomers and modulate the biochemical or pharmacological activities of the protomers (Table 1). Non-obligatory GPCR heterodimers account for the major population and exhibit diverse modulatory functions. In human embryonic kidney (HEK) 293 cells expressing the angiotensin II receptor (AT1)-bradykinin receptor (B2) heterodimer, angiotensin II triggered inositol triphosphate $\left(\mathrm{IP}_{3}\right)$ accumulation much more potently and effectively than it did in the cells expressing AT1 alone, whereas $\mathrm{IP}_{3}$ accumulation by bradykinin was slightly weaker in cells expressing the AT1-B2 heterodimer than in the cells expressing only B2 (28). This enhancement was also detected in vivo, where AT1 and B2 were shown to form a heterodimer in smooth muscle, omental vessel, and platelets $(28,29)$.

The opioid receptor family is composed of three subtypes, namely, $\mu-, \delta$-, and $\kappa$-opioid receptors (MOR, DOR, and KOR), all of which mediate inhibition of cAMP production with different ligand-selectivity (30). Co-expression of MOR and DOR in HEK293 cells resulted in a 10-fold reduction in binding affinity of a synthetic MOR-selective agonist, DAMGO (31). Moreover, the MOR-DOR heterodimer differs in rank order of affinities for endogenous peptide ligands; Met-enkephalin, possessing the highest affinity for MOR among endogenous opioid peptides, exhibited twofold lower affinity to the MOR-DOR heterodimer, while the affinity of endomorphin-1 and Leu-enkephalin to the heterodimer was increased two to threefold, compared to MOR (31). Moreover, heterodimerization of MOR and DOR predominantly induced activation of a pertussis toxin-insensitive $\mathrm{G}$ protein, Gz in COS-7 cells, while monomeric or homodimeric MOR and DOR were coupled to a pertussis toxin-sensitive G protein, Gi (32). This is consistent with findings that the binding of ligands to the MOR-DOR heterodimer followed by signal transduction is resistant to pertussis toxin (32). A KOR-selective agonist, U69593, exhibited as potent and efficacious activities at the heterodimer as at KOR, whereas $6^{\prime}$-GNTI was a sixfold more potent agonist for the KOR-DOR heterodimer than for the KOR homodimer (33). More recently, $N$-naphthoyl- $\beta$-naltrex-amine (NNTA), a potent antagonist for MOR, was shown to manifest a prominent agonistic activity at MOR-DOR (34). In the mouse tail-flick assay, intrathecal NNTA elicited 100-fold greater antinociception, compared to intracerebroventricular administration (34). These heterodimerization-based pharmacological alterations are expected to provide crucial clues to understand why various in vivo pharmacological profiles are inconsistent with those from in vitro studies using cells expressing each opioid receptor alone and to develop more specific clinical agents for opioid receptors.

When an orexin receptor OR1 was co-expressed with a cannabinoid receptor CB1 in HEK293 cells, addition of a CB1-specific antagonist, SR-141716A, resulted in the suppression of orexintriggered phosphorylation of ERK1/2 (35). Likewise, an OR1specific antagonist, SB-674042, attenuated the ERK phosphorylation activated by a CB1 agonist, WIN55212-2 (35). These data verify the regulatory mechanism by which one GPCR protomer bound to an antagonist modulates the pharmacological profile of another GPCR protomer through heterodimerization.
Melanocortin receptor 3 (MC3R) and ghrelin receptor (GHSR) were found to be co-expressed in a number of neurons in the arcuate nucleus $(36,37)$. Co-transfection of MC3R and GHSR into COS-7 cells enhanced melanocortin-induced intracellular cAMP accumulation, compared with activation of MC3R in the absence of GHSR, whereas both agonist-independent basal and ghrelin-induced signaling of GHSR were diminished (36). These findings reveal mutual opposite signal modulation by each protomer and suggest that the molecular mechanism underlying a certain agonist-independent active conformation of a protomer is also involved in the regulation of the signaling functionalities of its partner GPCR in a heterodimer. Since MC3R and GHSR play pivotal roles in the orexigenic system, the MC3R-GHSR heterodimer is involved in hypothalamic body weight regulation.

There is increasing evidence for a pathological relevance of GPCR heterodimer. AT1-B2 heterodimer is highly likely to be functionally correlated with preeclampsia. The AT1-B2 heterodimer was more abundant on platelets of preeclamptic women than on platelets of normotensive pregnant women (29). Such increase in the number of heterodimers is due to enhanced expression of B2, as the expression level of B2 was elevated four to fivefold on platelets of preeclamptic women compared to platelets of normotensive pregnant women, whereas expression of AT1 was unchanged (29). Moreover, mobilization of intracellular calcium ions induced by angiotensin II was up-regulated 1.7- to 1.9-fold in platelets of preeclamptic women, compared to normotensive pregnant women $(28,29)$.

Heterodimerization between dopamine receptor subtypes, D1 and D2, has shown to be implicated in depression. The D1-D2 heterodimer was detected at higher levels in the post-mortem striatum of the patients compared to in normal subjects using co-immunoprecipitation and D1-D2 heteromer-selective antibodies (38). Moreover, dissociation of the D1-D2 heterodimer by an interfering peptide that disrupts the heteromer resulted in substantially reduced immobility in the forced swim test without affecting locomotor activity, and decreased escape failures in learned helplessness tests in rats (38). It should be noted that the heterodimerization between D1 and D2 leads to a drastic shift of G protein coupling; D1 and D2 monomer/homomer are coupled to Gs and $\mathrm{Gi}$, respectively, while $\mathrm{Gq} / 11$ is a major $\mathrm{G}$ protein-coupled to the D1-D2 heterodimer (39).

More recently, MOR-DOR heterodimer was found to play pivotal roles in the opioid system. An interaction-disrupting peptide fragment for the MOR-DOR heterodimer enhanced morphine analgesia and reduced anti-nociceptive tolerance to morphine in mice (40).

\section{HETERODIMERS AMONG REPRODUCTION - ASSOCIATED GPCRs}

\section{MELATONIN RECEPTOR}

Melatonin participates in reproductive functions via upregulation of the synthesis and secretion of $\mathrm{GnIH}$ in the hypothalamus of mammals and birds $(10,11)$. Moreover, melatonin receptors were also shown to be expressed in gonads (41), and melatonin significantly decreases testosterone secretion from LH/FSH-stimulated testes of European starlings before breeding (42). Two class A (rhodopsin-like) GPCRs for melatonin, MT1 and MT2, have been 
identified in mammals $(1,43)$. A human orphan GPCR, GPR50, sharing the highest sequence homology with MT1 and MT2, was shown to form a heterodimer with both receptors in HEK293 cells $(1,43)$. Moreover, heterodimerization of GPR50 with MT1 resulted in a marked reduction of the ability of MT1 to bind to ligands and to couple to $\mathrm{G}$ proteins, resulting in decreased in $\mathrm{Gi}$ protein-coupled intracellular signaling and $\beta$-arrestin - assisted internalization in HEK293 cells, whereas functions of MT2 were not affected $(1,43)$. These data indicate that GPR50 antagonizes MT1 but not MT2 via heterodimerization. In addition, this is the first report on the functional role of an orphan receptor as a protomer of a GPCR heterodimer.

\section{TACHYKININ RECEPTOR}

Tachykinins (TKs) are vertebrate and ascidian multifunctional brain/gut peptides involved in smooth muscle contraction, vasodilation, nociception, inflammation, neurodegeneration, and neuroprotection in a neuropeptidergic endocrine, paracrine fashion (44-48). The mammalian TK family consists of four major peptides: Substance $\mathrm{P}$ (SP), Neurokinin A (NKA), NKB, and Hemokinin-1/Endokinins (HK-1/EKs) (EK is a human homolog of mouse and rat $\mathrm{HK}-1)$. TK receptors belong to the class $\mathrm{A}$ GPCR family. Three subtypes of TK receptors, namely NK1, $\mathrm{NK} 2$, and NK3, have been identified in mammals, and several submammalian orthologs have been cloned or suggested by genomic database search. In the ascidian, Ciona intestinalis, authentic TK, and its cognate receptor, Ci-TK-I and Ci-TK-R were identified $(49,50)$. Recently, there are accumulating reports on reproductive roles of TKs as well as the expression of TKs and TK receptors in genital organs of mammals $(46,48,49$, 51-54). In C. intestinalis, Ci-TK-I enhances oocyte growth from the vitellogenic stage to the post-vitellogenic stage via upregulation of gene expression and enzymatic activity of several proteases such as cathepsin D, carboxypeptidase B1, and chymotrypsin (55-57). Over the past few years, there has been increasing evidence that $\mathrm{NKB}$ plays a central role in the direct enhancement of GnRH synthesis and release in the hypothalamus of mammals, eventually leading to the recognition of novel regulatory function in sexual maturation and reproduction [(58-65)].

Only one tachykinin receptor-relevant heterodimer has thus far been identified. NK1 and an opioid receptor subtype, MOR, were shown to co-exist in pain-processing brain regions, including trigeminal dorsal horn neurons, and to heterodimerize in co-transfected HEK293 cells (66). NK1-MOR heterodimerization altered their internalization and resensitization profile, while ligand binding and signaling intensities of the protomers were not affected. In cells expressing NK1-MOR heterodimer, both DAMGO and SP induced the recruitment of $\beta$-arrestin to the plasma membrane and internalization of NK1-MOR heterodimers with $\beta$-arrestin into the same endosomal compartment (66). Recent studies also verified that other tachykinin receptors, such as NK3, are co-localized with various GPCRs including kisspeptin receptors and opioid receptors (59). Consequently, tachykinin receptors are expected to form heterodimers with a wide variety of GPCRs, which, in turn, are potentially involved in the molecular mechanisms underlying novel reproductive functions.

\section{GnRH RECEPTOR}

Gonadotropin-releasing hormones are hypothalamic decapeptides that regulate the HPG axis to control reproduction by releasing gonadotropins, $\mathrm{FSH}$, and $\mathrm{LH}$ from the pituitary in vertebrates (Figure 1). The endogenous receptors, GnRHRs, which belong to the Class A GPCR family, have also been shown to possess species-specific paralogs forms in vertebrates. Type I GnRHRs, which completely lack a C-terminal tail region, are restricted to humans, rodents, and cows (14-16, 67, 68). Type II GnRHRs, which bear a C-terminal tail, are widely distributed throughout almost all vertebrates, whereas the type II gnrhr gene is silenced due to a deletion of functional domains or interruption of fulllength translation by the presence of a stop codon in humans, chimpanzees, cows, and sheep (14-16, 67, 68). To date, no convincing evidence for heterodimerization of GnRHRs in native tissues has been provided.

Gonadotropin-releasing hormones have also been identified in a wide range of invertebrates that lack a pituitary (Kawada et al., forthcoming). To date, seven GnRH peptides (tGnRH-3 to -8 and $\mathrm{Ci}-\mathrm{GnRH}-\mathrm{X}$ ) and four $\mathrm{GnRH}$ receptor subtypes (Ci-GnRHR-1 to -4) have been identified in C. intestinalis (69-71). Molecular phylogenetic analysis indicates that Ci-GnRHR2 (R2), R3, and R4 are Ciona-specific paralogs of $\mathrm{R} 1$ generated via gene duplication (70, 72). Only $\mathrm{R} 1$ activated $\mathrm{IP}_{3}$ generation followed by intracellular $\mathrm{Ca}^{2+}$ mobilization in response to $\mathrm{tGnRH}-6$, whereas $\mathrm{R} 2$ and R3 exclusively stimulate cAMP production in response to multiple tGnRHs; tGnRH-6, -7, and -8 exhibited near-equipotent cAMP production via $\mathrm{R} 2$, which was 100 -fold more potent than $\mathrm{tGnRH}$ $3,-4$, and -5 . tGnRH-3 and -5 specifically triggered R3-mediated cAMP production $(70,73-75)$. R4 is devoid of binding to any tGnRHs or of activating any signaling pathways (70). Recently, we have shown that the orphan paralog, R4, is responsible for the finetuning of the GnRHergic signaling via heterodimerization with R1. The R1-R4 heterodimer elicited a 10-fold more potent $\mathrm{Ca}^{2+}$ mobilization than R1 monomer/homodimer in a tGnRH-6-selective manner, while cAMP production by $\mathrm{R} 1$ was not modulated via heterodimerization with R4 (73). The R1-R4 heterodimer potentiated translocation of both $\mathrm{Ca}^{2+}$-dependent PKC $\alpha$ by tGnRH- 6 and $\mathrm{Ca}^{2+}$-independent PKC $\zeta$ by $\mathrm{tGnRH}-5$ and -6 , eventually leading to upregulation of ERK phosphorylation, compared with R1 alone (73). These results provide evidence that the species-specific GnRHR orphan paralog, R4, serves as an endogenous modulator for the fine-tuning of the activation of PKC subtype-selective signal transduction via heterodimerization with R1. R4 was also shown to heterodimerize with R2 specifically in test cells of vitellogenic oocytes (74). Of particular interest is that the R2-R4 heterodimer in HEK293 cells decreased cAMP production in a non-ligand selective manner via a shift from activation of Gs protein to Gi protein by R2, compared with R2 monomer/homodimer (74). Considering that R1-R4 elicited a 10 -fold more potent $\mathrm{Ca}^{2+}$ mobilization than R1 monomer/homodimer in a ligand selective manner but did not affect cAMP production, these results indicate that $\mathrm{R} 4$ regulates differential $\mathrm{GnRH}$ signaling cascades via heterodimerization with $\mathrm{R} 1$ and $\mathrm{R} 2$ as an endogenous allosteric modulator. Collectively, these studies suggest that heterodimerization among GnRHR paralogs, including the species-specific orphan receptor subtype, is involved in rigorous and diversified GnRHergic signaling in a protochordate lacking an HPG axis. 


\section{LH RECEPTOR}

Luteinizing hormone is a central pituitary peptide hormone responsible for gonadal maturation (Figure 1). A single GPCR for LH has been identified in mammals. Although no LH receptorcontaining GPCR heterodimer has been detected, studies on LH homodimers suggests that LH can also serve as a multifunctional protomer in various GPCR heterodimers. Co-expression of a ligand-binding-deficient $\mathrm{LH}$ receptor mutant and a signalingdeficient $\mathrm{LH}$ receptor mutant resulted in the restoration of normal gonadal and genital function in transgenic mice, indicating that LH receptor functions as a dimer in vivo (76).

\section{PROSTAGLANDIN RECEPTOR}

Prostanoids consist of prostaglandin (PG) D, $\mathrm{PGE}_{2}, \mathrm{PGF}_{2 \alpha}, \mathrm{PGI}_{2}$, and thromboxane $\mathrm{A}_{2}$ and are responsible for a variety of actions in various tissues including the relaxation and contraction of various types of smooth muscles, pain transmission, fever generation, and sleep induction (77). Numerous studies have also proved that ovulation, corpus luteum development and regression are mediated by PGs (78-80). To date, eight GPCRs for PGs have been identified in mammals. Heterodimerization of a $\mathrm{PGE}_{2}$ receptor, EP1, with $\beta 2$ adrenergic receptor $(\beta 2 \mathrm{AR})$ caused considerable reduction in cAMP production by $\beta 2 \mathrm{AR}$ via enhancement of the dissociation of Gs protein from $\beta 2 A R$ in the presence of endogenous or synthetic EP1 agonists in primary cultures of airway smooth muscle or COS-7 cells (81). Of importance in the functional regulation by the GPCR heterodimer is that EP1 have a direct inhibitory effects on bronchodilatory signaling but rather modulates the function of the $\beta 2 \mathrm{AR}$. These findings strongly suggest that the heterodimerization of $\beta 2 \mathrm{AR}$ with EP1 causes the $\beta 2$-agonist resistance found in asthma (81).

\section{EFFECTS OF GPCR HETERODIMERIZATION ON DIVERSIFICATION OF ANIMAL SPECIES AND BIOLOGICAL FUNCTION}

G protein-coupled receptors are largely categorized into two groups. The first group consists of GPCRs conserved as authentic "homologs" in various species, and the second one includes species-specific GPCRs. The latter is further classified into GPCRs for species-specific ligands and subtypes of GPCRs for highly conserved ligands in various species. For instance, $C$. intestinalis GnRH receptors consists of four GPCRs as stated above: R1, R2, R3, and R4. Phylogenetic tree and biochemical analyses proved that R1 is structurally and functionally homologous to vertebrate $\mathrm{GnRH}$ receptors, whereas $\mathrm{R} 2, \mathrm{R} 3$, and $\mathrm{R} 4$ are $C$. intestinalis-specific paralogs that occurred via gene duplication in the Ciona evolutionary lineage (70, Kawada et al., forthcoming). Likewise, speciesspecific GnRHR-III has been identified in teleost species $(14,15)$, and lamprey has also three GnRHRs which are genetically independent of teleost GnRHR subtypes (16). Such species-specific GPCR paralogs are thought to determine the functional diversity and physiological regulatory systems, because GPCR paralogs can form species-specific GPCR heterodimers, which, if expressed in the same cells, control the unique expansion and fine-tuning of GPCR-mediated signaling pathways (Figure 2), as shown for $C$. intestinalis GnRHRs $(73,74)$. In other words, heterodimerization involving species-specific GPCRs is highly likely to contribute to the evolution and diversification of organisms to a large extent.

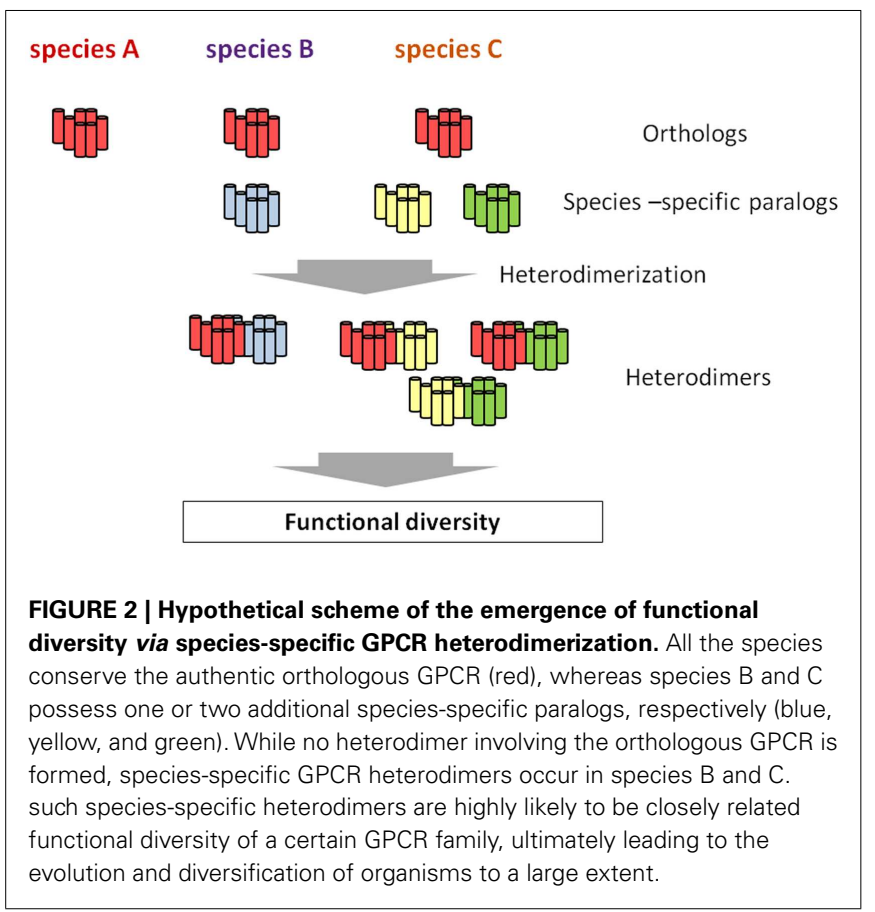

\section{CONCLUSION AND PERSPECTIVES}

To date, GPCR heterodimerization has attracted keen attentions in light of biochemical and pharmacological features of GPCRs and the development of drugs with high selectivity, given that GPCR heterodimerization has been explored almost exclusively in mammals, except for C. intestinalis GnRHRs. Nevertheless, recent studies in various fields suggest that GPCR heterodimerization plays crucial roles in the regulation of the HPG axis and the evolution and diversification of reproductive functions. In this regard, of special interest is whether kisspeptin receptors or $\mathrm{GnIH}$ receptors heterodimerize with any GPCRs. Moreover, heterodimerization involving species-specific GPCR paralogs is expected to be responsible for the emergence of unique physiological functions in the respective organisms. Accordingly, combined with the fact that GPCRs form corresponding heterodimers after translation, investigation of GPCR heterodimerization in non-mammalian organisms will provide novel insight into the generation of biodiversity directed by a post-translational protein interaction.

In keeping with this issue, of particular interest is the clarification of the in vivo functional correlation between GPCR heterodimerization and biological events. Real-time imaging of GPCR heterodimerization could enable the visualization of biological functions of GPCR heterodimers of interest. Although this experimental strategy is unlikely to be applied to mammals, organisms equipped with transparent or semi-transparent skins, including ascidian, medaka, or zebrafish, are useful for live-imaging of GPCR heterodimers (50). Such studies are currently in progress in our laboratory.

\section{ACKNOWLEDGMENTS}

This study was in part financially supported by JSPS (to Honoo Satake, Masato Aoyama, and Tsuyoshi Kawada). 


\section{REFERENCES}

1. Levoye A, Dam J, Ayoub MA, Guillaume JL, Couturier C, Delagrange $\mathrm{P}$, et al. The orphan GPR50 receptor specifically inhibits MT1 melatonin receptor function through heterodimerization. EMBO J (2006) 25:3012-23. doi:10.1038/sj.emboj. 7601193

2. Pin JP, Neubig R, Bouvier M, Devi L, Filizola M, Javitch JA, et al. International Union of Basic and Clinical Pharmacology. LXVII. Recommendations for the recognition and nomenclature of $\mathrm{G}$ protein-coupled receptor heteromultimers. Pharmacol Rev (2007) 59:5-13. doi:10.1124/ pr.59.1.5

3. Satake H, Sakai T. Recent advances and perceptions in studies of heterodimerization between $\mathrm{G}$ proteincoupled receptors. Protein Pept Lett (2008) 15:300-8. doi:10.2174/ 092986608783744207

4. Milligan G. G protein-coupled receptor hetero-dimerization: contribution to pharmacology and function. Br J Pharmacol (2009) 158:5-14. doi:10.1111/j.1476-5381. 2009.00169.x

5. Del Burgo LS, Milligan G. Heterodimerisation of $\mathrm{G}$ proteincoupled receptors: implications for drug design and ligand screening. Expert Opin Drug Discov (2010) 5:461-74. doi:10.1517/17460441003720467

6. Kamal M, Jockers R. Biological significance of GPCR heteromerization in the neuro-endocrine system. Front Endocrinol (Lausanne) (2011) 2:2. doi:10.3389/fendo.2011.00002

7. Tadagaki K, Jockers R, Kamal M. History and biological significance of GPCR heteromerization in the neuroendocrine system. Neuroendocrinology (2012) 95:223-31. doi: $10.1159 / 000330000$

8. Goupil E, Laporte SA, Hébert TE. Functional selectivity in GPCR signaling: understanding the full spectrum of receptor conformations. Mini Rev Med Chem (2012) 12:817-30. doi:10.2174/138955712800959143

9. Borroto-Escuela DO, RomeroFernandez W, Garriga P, Ciruela F, Narvaez M, Tarakanov AO, et al. G protein-coupled receptor heterodimerization in the brain. Methods Enzymol (2013) 521:281-94. doi:10.1016/B978-012-391862-8.00015-6

10. Tsutsui K, Ubuka T, Bentley GE, Kriegsfeld LJ. Gonadotropininhibitory hormone $(\mathrm{GnIH})$ : discovery, progress and prospect. Gen Comp Endocrinol (2012) 177:
305-14. doi:10.1016/j.ygcen.2012. 02.013

11. Ubuka T, Son YL, Tobari Y, Tsutsui K. Gonadotropin-inhibitory hormone action in the brain and pituitary. Front Endocrinol (Lausanne) (2012) 3:148. doi:10.3389/ fendo.2012.00148

12. Christensen A, Bentley GE, Cabrera $\mathrm{R}$, Ortega $\mathrm{HH}$, Perfito $\mathrm{N}, \mathrm{Wu}$ TJ, et al. Hormonal regulation of female reproduction. Horm Metab Res (2012) 44:587-91. doi:10.1055/ s-0032-1306301

13. Franceschini I, Desroziers E. Development and aging of the kisspeptinGPR54 system in the mammalian brain: what are the impacts on female reproductive function? Front Endocrinol (Lausanne) (2013) 4:22. doi:10.3389/fendo.2013.00022

14. Okubo K, Nagahama Y. Structural and functional evolution of gonadotropin-releasing hormone in vertebrates. Acta Physiol (Oxf) (2008) 193:3-15. doi:10.1111/j. 1748-1716.2008.01832.x

15. Lindemans $M$, Janssen $T$, Beets I, Temmerman L, Meelkop E, Schoofs L. Gonadotropin-releasing hormone and adipokinetic hormone signaling systems share a common evolutionary origin. Front Endocrinol (Lausanne) (2011) 2:16. doi:10.3389/fendo.2011.00016

16. Sower SA, Decatur WA, Joseph NT, Freamat M. Evolution of vertebrate GnRH receptors from the perspective of a basal vertebrate. Front Endocrinol (Lausanne) (2012) 3:140. doi:10.3389/fendo. 2012.00140

17. Kanda S, Oka Y. Structure, synthesis, and phylogeny of kisspeptin and its receptor. Adv Exp Med Biol (2013) 784:9-26. doi:10.1007/978-1-46146199-9_2

18. Gopurappilly R, Ogawa S, Parhar IS. Functional significance of $\mathrm{GnRH}$ and kisspeptin, and their cognate receptors in teleost reproduction. Front Endocrinol (Lausanne) (2013) 4:24. doi:10.3389/fendo. 2013.00024

19. Fanelli F, De Benedetti PG. Update 1 of: computational modeling approaches to structure-function analysis of $G$ protein-coupled receptors. Chem Rev (2011) 111:R438535. doi:10.1021/cr100437t

20. Fuxe K, Borroto-Escuela DO, Marcellino D, Romero-Fernandez W, Frankowska M, Guidolin $\mathrm{D}$, et al. GPCR heteromers and their allosteric receptorreceptor interactions. Curr Med Chem (2012) 19:356-63. doi:10.2174/092986712803414259
21. Milligan G, Smith NJ. Allosteric modulation of heterodimeric G-protein-coupled receptors. Trends Pharmacol Sci (2007) 12:615-20. doi:10.1016/j.tips.2007.11.001

22. Kaupmann K, Malitschek B, Schuler V, Heid J, Froestl W, Beck P, et al. GABA(B)-receptor subtypes assemble into functional heteromeric complexes. Nature (1998) 396:6837. doi:10.1038/25360

23. Duthey B, Caudron S, Perroy J, Bettler B, Fagni L, Pin JP, et al. A single subunit (GB2) is required for G-protein activation by the heterodimeric $\mathrm{GABA}(\mathrm{B})$ receptor. J Biol Chem (2002) 277:3236-41. doi: 10.1074/jbc.M108900200

24. Pin JP, Kniazeff J, Liu J, Binet V, Goudet C, Rondard P, et al. Allosteric functioning of dimeric class C G-protein-coupled receptors. FEBS J (2005) 272:294755. doi:10.1111/j.1742-4658.2005. 04728.x

25. Nelson G, Hoon MA, Chandrashekar J, Zhang Y, Ryba NJ, Zuker CS. Mammalian sweet taste receptors. Cell (2001) 106:381-90. doi:10. 1016/S0092-8674(01)00451-2

26. Nelson G, Chandrashekar J, Hoon MA, Feng L, Zhao G, Ryba NJ, et al. An amino-acid taste receptor. Nature (2002) 416:199-202. doi:10. 1038/nature726

27. Xu H, Staszewski L, Tang H, Adler E, Zoller M, Li X. Human receptors for sweet and umami taste. Proc Natl Acad Sci USA (2004) 101:14258-63. doi:10.1073/pnas.0404384101

28. AbdAlla S, Lother H, Quitterer U. AT1-receptor heterodimers show enhanced G-protein activation and altered receptor sequestration. Nature (2000) 407:94-8. doi:10.1038/35024095

29. AbdAlla S, Lother H, el Massiery A, Quitterer U. Increased AT(1) receptor heterodimers in preeclampsia mediate enhanced angiotensin II responsiveness. Nat Med (2001) 7:1003-9. doi:10.1038/nm0901-1003

30. Kieffer BL. Opioids: first lessons from knockout mice. Trends Pharmacol Sci (1999) 20:19-26. doi:10. 1016/S0165-6147(98)01279-6

31. Gomes I, Jordan BA, Gupta A, Trapaidze N, Nagy V, Devi LA. Heterodimerization of $\mathrm{mu}$ and delta opioid receptors: a role in opiate synergy. J Neurosci (2000) 20:RC110.

32. Fan T, Varghese G, Nguyen T, Tse R, O’Dowd BF, George SR. A role for the distal carboxyl tails in generating the novel pharmacology and $G$ protein activation profile of $\mathrm{mu}$ and delta opioid receptor hetero-oligomers. J Biol Chem (2005) 280:38478-88. doi:10.1074/ jbc.M505644200

33. Waldhoer M, Fong J, Jones RM, Lunzer MM, Sharma SK, Kostenis E, et al. A heterodimerselective agonist shows in vivo relevance of $\mathrm{G}$ protein-coupled receptor dimers. Proc Natl Acad Sci USA (2005) 102:9050-5. doi:10. 1073/pnas.0501112102

34. Yekkirala AS, Lunzer MM, McCurdy CR, Powers MD, Kalyuzhny AE, Roerig SC, et al. N-naphthoyl-betanaltrexamine (NNTA), a highly selective and potent activator of $\mu /$ kappa-opioid heteromers. Proc Natl Acad Sci USA (2011) 108:5098103. doi:10.1073/pnas. 1016277108

35. Ellis J, Pediani JD, Canals M, Milasta S, Milligan G. Orexin1receptor-cannabinoid CB1 receptor heterodimerization results in both ligand-dependent and -independent coordinated alterations of receptor localization and function. $J$ Biol Chem (2006) 281:38812-24. doi:10.1074/jbc.M602494200

36. Rediger A, Piechowski CL, Yi CX, Tarnow P, Strotmann R, Grüters A, et al. Mutually opposite signal modulation by hypothalamic heterodimerization of ghrelin and melanocortin-3 receptors. J Biol Chem (2011) 286:39623-31. doi:10. 1074/jbc.M111.287607

37. Rediger A, Piechowski CL, Habegger $\mathrm{K}$, Grüters $\mathrm{A}$, Krude $\mathrm{H}$, Tschöp MH, et al. MC4R dimerization in the paraventricular nucleus and GHSR/MC3R heterodimerization in the arcuate nucleus: is there relevance for body weight regulation? Neuroendocrinology (2012) 9:277-88. doi:10.1159/000334903

38. Pei L, Li S, Wang M, Diwan M, Anisman H, Fletcher PJ, et al. Uncoupling the dopamine D1-D2 receptor complex exerts antidepressant-like effects. Nat Med (2010) 16:1393-5. doi:10.1038/nm.2263

39. Rashid AJ, So CH, Kong MM, Furtak T, El-Ghundi M, Cheng $\mathrm{R}$, et al. D1-D2 dopamine receptor heterooligomers with unique pharmacology are coupled to rapid activation of $\mathrm{Gq} / 11$ in the striatum. Proc Natl Acad Sci USA (2007) 104:654-9. doi:10.1073/ pnas.0604049104

40. He SQ, Zhang ZN, Guan JS, Liu HR, Zhao B, Wang HB, et al. Facilitation of $\mu$-opioid receptor activity by preventing $\delta$-opioid receptormediated codegradation. Neuron 
(2011) 69:120-31. doi:10.1016/j. neuron.2010.12.001

41. McGuire NL, Bentley GE. Neuropeptides in the gonads: from evolution to pharmacology. Front Pharmacol (2010) 1:114. doi:10.3389/ fphar.2010.00114

42. McGuire NL, Kangas K, Bentley GE. Effects of melatonin on peripheral reproductive function: regulation of testicular $\mathrm{GnIH}$ and testosterone. Endocrinology (2011) 152:3461-70. doi:10.1210/en.2011-1053

43. Levoye A, Dam J, Ayoub MA, Guillaume JL, Jockers R. Do orphan G-protein-coupled receptors have ligand-independent functions? New insights from receptor heterodimers. EMBO Rep (2006) 7:1094-8. doi:10.1038/sj.embor.7400838

44. Severini C, Improta G, FalconieriErspamer G, Salvadori S, Erspamer V. The tachykinin peptide family. Pharmacol Rev (2002) 54:285-322.

45. Almeida TA, Rojo J, Nieto PM, Pinto FM, Hernandez M, Martin JD, et al. Tachykinins and tachykinin receptors: structure and activity relationships. Curr Med Chem (2005) 11:2045-81. doi:10. 2174/0929867043364748

46. Satake H, Kawada T. Overview of the primary structure, tissuedistribution, and functions of tachykinins and their receptors. Curr Drug Targets (2006) 7:963-74. doi:10.2174/ 138945006778019273

47. Page NM. Characterization of the gene structures, precursor processing and pharmacology of the endokinin peptides. Vascul Pharmacol (2006) 45:200-8. doi:10.1016/j.vph.2005.08.028

48. Satake H, Aoyama M, Sekiguchi $\mathrm{T}$, Kawada T. Insight into molecular and functional diversity of tachykinins and their receptors. Protein Pept Lett (2013) 20:615-27. doi: 10.2174/0929866511320060002

49. Satake H, Ogasawara M, Kawada T, Masuda K, Aoyama M, Minakata $\mathrm{H}$, et al. Tachykinin and tachykinin receptor of an ascidian, Ciona intestinalis: evolutionary origin of the vertebrate tachykinin family. $J$ Biol Chem (2004) 279:53798-805. doi:10.1074/jbc.M408161200

50. Satake H, Kawada T, Aoyama M, Sekiguchi T, Sakai T. Ascidians: new model orgnanisms for reproductive endocrinology. In: Aimaretti G, Marzullo P, Prodam F editors. Update on Mechanisms of Hormone Action - Focus on Metabolism, Growth and Reproductions. Vienna: IN-TECH (2011). p. 313-36.
51. Pennefather JN, Patak E, Ziccone S, Lilley A, Pinto FM, Page NM, et al. Regulation of the stimulant actions of neurokinin a and human hemokinin-1 on the human uterus: a comparison with histamine. Biol Reprod (2006) 75:334-41. doi:10. 1095/biolreprod.106.051508

52. Ravina CG, Seda M, Pinto FM, Orea A, Fernandez-Sanchez M, Pintado $\mathrm{CO}$, et al. A role for tachykinins in the regulation of human sperm motility. Hum Reprod (2007) 22:1617-25. doi:10.1093/ humrep/dem069

53. Patak E, Pennefather JN, Gozali M, Candenas ML, Kerr K, Exintaris B, et al. Functional characterisation of hemokinin-1 in mouse uterus. Eur J Pharmacol (2008) 601:148-53. doi: 10.1016/j.ejphar.2008.10.036

54. Pinto FM, Ravina CG, Subiran N, Cejudo-Román A, Fernández-Sánchez $\mathrm{M}$, Irazusta $\mathrm{J}$, et al. Autocrine regulation of human sperm motility by tachykinins. Reprod Biol Endocrinol (2010) 8:104. doi:10.1186/1477-7827-8-104

55. Aoyama M, Kawada T, Fujie M, Hotta K, Sakai T, Sekiguchi T, et al. A novel biological role of tachykinins as an up-regulator of oocyte growth: identification of an evolutionary origin of tachykininergic functions in the ovary of the ascidian, Ciona intestinalis. Endocrinology (2008) 149:4346-56. doi:10.1210/en.20080323

56. Aoyama M, Kawada T, Satake H. Localization and enzymatic activity profiles of the proteases responsible for tachykinin-directed oocyte growth in the protochordate, Ciona intestinalis. Peptides (2012) 34:18692. doi:10.1016/j.peptides.2011.07. 019

57. Kawada T, Ogasawara M, Sekiguchi $\mathrm{T}$, Aoyama M, Hotta K, Oka $\mathrm{K}$, et al. Peptidomic analysis of the central nervous system of the protochordate, Ciona intestinalis: homologs and prototypes of vertebrate peptides and novel peptides. Endocrinology (2011) 152:2416-27. doi:10.1210/en.2010-1348

58. Topaloglu AK, Reimann F, Guclu M, Yalin AS, Kotan LD, Porter KM, et al. TAC3 and TACR3 mutations in familial hypogonadotropic hypogonadism reveal a key role for Neurokinin B in the central control of reproduction. Nat Genet (2009) 41:354-8. doi:10.1038/ng.306

59. Rance NE, Krajewski SJ, Smith MA, Cholanian M, Dacks PA. Neurokinin $B$ and the hypothalamic regulation of reproduction. Brain Res
(2010) 1364:116-28. doi:10.1016/j. brainres.2010.08.059

60. Lasaga M, Debeljuk L. Tachykinins and the hypothalamo-pituitarygonadal axis: an update. Peptides (2011) 32:1972-8. doi:10.1016/j. peptides.2011.07.009

61. Molnár CS, Vida B, Sipos MT, Ciofi P, Borsay BÁ, Rácz K, et al. Morphological evidence for enhanced kisspeptin and neurokinin B signaling in the infundibular nucleus of the aging man. Endocrinology (2012) 153:5428-39. doi:10.1210/ en.2012-1739

62. Grachev P, Li XF, Kinsey-Jones JS, di Domenico AL, Millar RP, Lightman SL, et al. Suppression of the GnRH pulse generator by neurokinin $\mathrm{B}$ involves a $\kappa$-opioid receptordependent mechanism. Endocrinology (2012) 153:4894-904. doi:10. 1210/en.2012-1574

63. Hrabovszky E, Sipos MT, Molnár CS, Ciofi P, Borsay BÁ, Gergely $\mathrm{P}$, et al. Low degree of overlap between kisspeptin, neurokinin $\mathrm{B}$, and dynorphin immunoreactivities in the infundibular nucleus of young male human subjects challenges the KNDy neuron concept. Endocrinology (2012) 153:4978-89. doi:10.1210/en.2012-1545

64. Gill JC, Navarro VM, Kwong C, Noel SD, Martin C, Xu S, et al. Increased neurokinin B (Tac2) expression in the mouse arcuate nucleus is an early marker of pubertal onset with differential sensitivity to sex steroid-negative feedback than Kiss1. Endocrinology (2012) 153:4883-93. doi:10.1210/en.20121529

65. Ruiz-Pino F, Navarro VM, Bentsen AH, Garcia-Galiano D, SanchezGarrido MA, Ciofi P, et al. Neurokinin $\mathrm{B}$ and the control of the gonadotropic axis in the rat: developmental changes, sexual dimorphism, and regulation by gonadal steroids. Endocrinology (2012) 153:4818-29. doi:10.1210/ en.2012-1287

66. Pfeiffer M, Kirscht S, Stumm R, Koch T, Wu D, Laugsch $M$, et al. Heterodimerization of substance $\mathrm{P}$ and mu-opioid receptors regulates receptor trafficking and resensitization. $J$ Biol Chem (2003) 278:51630-7. doi:10.1074/ jbc.M307095200

67. Kah O, Lethimonier C, Somoza G, Guilgur LG, Vaillant C, Lareyre JJ. GnRH and GnRH receptors in metazoa: a historical, comparative, and evolutive perspective. Gen Comp Endocrinol (2007) 153:34664. doi:10.1016/j.ygcen.2007.01.030
68. Millar RP, Pawson AJ, Morgan K, Rissman EF, Lu ZL. Diversity of actions of GnRHs mediated by ligand-induced selective signaling. Front Neuroendocrinol (2008) 29:17-35. doi:10.1016/j.yfrne.2007. 06.002

69. Adams BA, Tello J, Erchegyi J, Warby C, Hong DJ, Akinsanya KO, et al. Six novel gonadotropin-releasing hormones are encoded as triplets on each of two genes in the protochordate, Ciona intestinalis. Endocrinology (2003) 144:1907-19. doi:10. 1210/en.2002-0216

70. Tello JA, River J, Sherwood NM. Tunicate gonadotropin-releasing hormone $(\mathrm{GnRH})$ peptides selectively activate Ciona intestinalis GnRH receptors and the green monkey type II GnRH receptor. Endocrinology (2005) 146:4061-73. doi:10.1210/en.2004-1558

71. Kawada T, Aoyama M, Okada I, Sakai T, Sekiguchi T, Ogasawara $\mathrm{M}$, et al. A novel inhibitory gonadotropin-releasing hormonerelated neuropeptide in the ascidian, Ciona intestinalis. Peptides (2009) 30:2200-5. doi:10.1016/j.peptides. 2009.08.014

72. Kusakabe T, Mishima S, Shimada I, Kitajima Y, Tsuda M. Structure, expression, and cluster organization of genes encoding gonadotropinreleasing hormone receptors found in the neural complex of the ascidian Ciona intestinalis. Gene (2003) 322:77-84. doi:10.1016/j. gene.2003.08.013

73. Sakai T, Aoyama M, Kusakabe T, Tsuda M, Satake H. Functional diversity of signaling pathways through G protein-coupled receptor heterodimerization with a species-specific orphan receptor subtype. Mol Biol Evol (2010) 27: 1097-106. doi:10.1093/molbev/ msp319

74. Sakai T, Aoyama M, Kawada T, Kusakabe T, Tsuda M, Satake H. Evidence for differential regulation of GnRH signaling via heterodimerization among GnRH receptor paralogs in the protochordate, Ciona intestinalis. Endocrinology (2012) 153:1841-9. doi:10.1210/en.20111668

75. Kusakabe TG, Sakai T, Aoyama M, Kitajima Y, Miyamoto Y, Takigawa T, et al. A conserved non-reproductive GnRH system in chordates. PLoS ONE (2012) 7:e41955. doi:10.1371/ journal.pone.0041955

76. Rivero-Muller A, Chou YY, Ji I, Lajic S, Hanyaloglu AC, Jonas K, et al. Rescue of defective $\mathrm{G}$ proteincoupled receptor function in vivo 
by intermolecular cooperation. Proc Natl Acad Sci USA (2010) 107:231924. doi:10.1073/pnas.0906695106

77. Narumiya S, Sugimoto Y, Ushikubi F. Prostanoid receptors: structures, properties, and functions. Physiol Rev (1999) 79:1193-226.

78. Matsui M, Miyamoto A. Evaluation of ovarian blood flow by colour Doppler ultrasound: practical use for reproductive management in the cow. Vet J (2009) 181:232-40. doi: 10.1016/j.tvjl.2008.02.027

79. Fujimori C, Ogiwara K, Hagiwara A, Rajapakse S, Kimura A, Takahashi T. Expression of cyclooxygenase-2 and prostaglandin receptor $\mathrm{EP} 4 \mathrm{~b}$ mRNA in the ovary of the medaka fish, Oryzias latipes: possible involvement in ovulation. $\mathrm{Mol}$ Cell Endocrinol (2011) 332:67-77. doi:10.1016/j.mce.2010.09.015

80. Takahashi T, Fujimori C, Hagiwara A, Ogiwara K. Recent advances in the understanding of teleost medaka ovulation: the roles of proteases and prostaglandins. Zool Sci (2013) 30:239-47. doi:10.2108/zsj. 30.239

81. McGraw DW, Mihlbachler KA, Schwarb MR, Rahman FF, Small $\mathrm{KM}$, Almoosa KF, et al. Airway smooth muscle prostaglandinEP1 receptors directly modulate beta2-adrenergic receptors within a unique heterodimeric complex. $J$
Clin Invest (2006) 116:1400-9. doi: 10.1172/JCI25840

Conflict of Interest Statement: The authors declare that the research was conducted in the absence of any commercial or financial relationships that could be construed as a potential conflict of interest.

Received: 06 June 2013; accepted: 31 July 2013; published online: 15 August 2013.

Citation: Satake H, Matsubara S, Aoyama $M$, Kawada $T$ and Sakai $T$ (2013) GPCR heterodimerization in the reproductive system: functional regulation and implication for biodiversity. Front. Endocrinol. 4:100. doi: 10.3389/fendo.2013.00100

This article was submitted to Frontiers in Experimental Endocrinology, a specialty of Frontiers in Endocrinology.

Copyright (๑) 2013 Satake, Matsubara, Aoyama, Kawada and Sakai. This is an open-access article distributed under the terms of the Creative Commons Attribution License (CC BY). The use, distribution or reproduction in other forums is permitted, provided the original author(s) or licensor are credited and that the original publication in this journal is cited, in accordance with accepted academic practice. No use, distribution or reproduction is permitted which does not comply with these terms. 